\title{
Expression levels of Tyro3 Receptor Kinase in the Decidua of the First Trimester Unexplained Recurrent Pregnancy Loss
}

\section{Esma Kirimlioglu ${ }^{1}$, Farida Qulieva ${ }^{1}$, Mehmet Simsek ${ }^{2}$ and Necdet Demir ${ }^{1 *}$}

${ }^{1}$ Department of Histology and Embryology, Faculty of Medicine, Akdeniz University, Turkey

${ }^{2}$ Department of OB/GYN, Faculty of Medicine, Akdeniz University, Turkey

*Corresponding author: Necdet Demir, Department of Histology and Embryology, Faculty of Medicine, Akdeniz University, Antalya, Turkey, Tel: +905322051013; Email: ndemir@ akdeniz.edu.tr

\section{Research Article \\ Volume 6 Issue 1}

Received Date: January 19, 2021

Published Date: February 04, 2021

DOI: $10.23880 /$ oajg-16000210

\section{Abstract}

Spontaneous loss is seen $12-15 \%$ in all pregnancies. More than $\% 50$ of those patients do not have a defined etiology, so they are named unexplained Recurrent Pregnancy Loss (URPL). Studies in recent years have made us think that Pregnancy Losses may be related to insufficient decidualization and undetected prothrombotic problems.

Tyro3 receptor kinase (RTK) is a member of TAM receptors and has been reported to have an important role in migration, Epithelial-mesenchymal transition (EMT), and platelet aggregation. There is not sufficient knowledge about expression levels of Tyro3 RTK in human first-trimester URPL decidua (URPLD).

By immunohistochemistry, immunoblotting, and qPCR, we investigated the expression of Tyro3 RTK in the decidua of human first-trimester termination healthy pregnancy (TPD)(n:6) and URPLD(n:6), and human endometrium (CE)(n:6).

Our results suggest that Tyro3 RTK expression significantly decreases with pregnancy and then returns to levels of CE for URPLD. Considering the role of Tyro3 RTK in platelet activation and thrombus formation, it suggests that this decrease observed in TPD may prevent the formation of prothrombosis which can prevent placental flow, and thus, hemostasis could be regulated in pregnancy through Tyro3 RTK. Although Tyro3 RTK decrease in TPD, locally increase on TPD, and also decrease on URPLD of Tyro3 RTK on DSCs makes us think, which Tyro3 RTK has a regulating role for EMT formation on DSCs and may participate in implantation and survival processing of the embryo through DSCs.

If those predictions are supported by further functional analyses, one of the causes of URPLD can be enlightened.

Keywords: Unexplained Recurrent Pregnancy Loss; Tyro3 Receptor Kinase; Decidual Stromal Cell; Pregnancy

Abbreviations: EMT: Epithelial-Mesenchymal Transition; URPL: unexplained Recurrent Pregnancy Loss; RTK: Receptor Kinase; TPD: Termination Healthy Pregnancy; PDZ: Primary Decidual Zone; SDZ: Secondary Decidual Area; CE: Control Endometrium.

\section{Highlights}

- Tyro3 receptor kinase distinctly decreases its expression in the decidua of human first-trimester termination healthy pregnancy.
- Total mRNA and protein expression levels of the Tyro3 receptor kinase increase in the decidua of human firsttrimester unexplained recurrent pregnancy losses compared with a healthy pregnancy.

- Expression and localization of Tyro3 receptor kinase decrease in decidual stromal cells of human firsttrimester unexplained recurrent pregnancy losses compared with a healthy pregnancy.

- Can decidual stromal cells during pregnancy be a regulator of thrombosis and epithelial-mesenchymal transition (EMT) via Tyro3 receptor kinase. 


\section{Open Access Journal of Gynecology}

\section{Introduction}

Fertilization occurs in fallopian tubes in 24-48 hours, after ovulation. Zygote shows cell differentiation and reaches as blastocyst to uterus lumen almost in the third day. A blastocyst has two layers the first of which called trophectoderm transforms into the extraembryonic organ and the second one called inner cell mass transforms into an embryo. The implantation of the blastocyst to the endometrium occurs in the 6-7 days after fertilization. Before implantation, mutual signaling occurs between the blastocyst and the maternal endometrium, and they undergo change [1-6]. Ovarian hormones and various cytokines have an essential role in successful pregnancy $[7,8]$. After Trophoblast cells have contact with uterine epithelium, decidualization occurs as the result of the differentiation in uterus endometrium [9].

ESCs are essential component of the endometrium. ESCs play a role in embryo recognition and selection [10]. When implantation occurs, ESCs surround the embryo and then interact with the embryo. ESCs produce a number of factors to mediate the activity of vascular endothelial cells, immune cells and epithelial cells [11-13]. In the decidualization process, ESCs undergo proliferation and differentiation under the influence of E2 and P4 and eventually become decidual cells $[10,14]$. Decidualization of ESCs is observed in the luteal phase and pregnancy endometrium. After trophoblast invasion, the avascular primary decidual zone (PZD) consisting of mature decidual cells in the proximal of the embryo, and the secondary decidual area (SDZ) in the distal periphery consisting of immature mitotic decidual cells surrounding the PDZ are observed $[15,16]$.

Cellular differentiation ability plays a very important role in human reproduction. While endometrial stromal cells undergo decidualization by showing mesenchymalepithelial change for the implantation and continuity of the embryo, luminal epithelial cells and decidual stromal cells with embryo/maternal signals gain the ability of acting like mesenchymal cells by showing the epithelial-mesenchymal transition. Thus, they also function in the development of the embryo by gaining the ability to accommodate invading trophoblasts [17].

Hemostasis, which is all the processes of stopping bleeding due to the deterioration of vascular integrity, is very important in pregnancy. Pregnancy, except for an increase in plasma concentration of several coagulants and a decrease in protein $\mathrm{S}$; is characterized by little or no change in plasma concentrations of thrombin or thrombin generation inhibitors [18]. Factor VII binds the transmembrane tissue factor to initiate hemostasis by creating thrombin.
Tissue factor expression increases in decidualized human endometrial cells during the luteal phase. Abnormally high local vascular permeability enables an increase in circulating factor VII. This increase contributes to the production of excess thrombin by increasing the expression of tissue factor from decidual stromal cells [19].

Miscarriage is an important emotional loss for all pregnant women and affects about $1 \%$ of them [20]. It has an incidence of more or less $12-15 \%$ in all pregnancies. $30 \%$ of them are terminated between implantation and the $6^{\text {th }}$ week of pregnancy. Most of $50 \%$ of those cases do not have a significant etiology. Three and more subsequent abortion in the clinic [20]; two and more subsequent abortion according to the application committee of American Reproductive Medicine society [21] is called 'Recurrent Pregnancy Loss' [22]. It is related to a chromosomal anomaly of conceptuses almost $50 \%$ of early pregnancy loss [23]. The other percent is associated with Anatomical anomaly [24], Hematological disease [25-30], microbial causes [31], Endocrinologic [23,32-34] and Immunologic [1,35-37] problems. It is indicated in literature that an important part of RPL may be related to Immune etiology and hematological.

While hemostasis and inflammation are two different cases, it is understood that they are relevant to each other. It is known nowadays that the molecules affecting hemostasis affect inflammation or just the opposite. TAM receptors are members of receptor tyrosine kinases (RTKs) which were cloned in 1991 and called orphan receptor until 1995 $[38,39]$. Immediately after, their ligands, Protein S (Pros1) and Growth arrest specific-6 (Gas6), have been defined $[40,41]$. TAM receptor kinesis (TAMRTK) is included by Tyro3 (Brt, Dtk, Etk-2, Rek, Rse, Sky and Tif), Axl (Ark, Tyro7 and Ufo), and Mertk (c-Eyk, Mertk, Nyk and Tyro12). In the extracellular side of TAMRTK have two immunoglobulins like domain and two fibronectin type3 repeats in series. Also, they have a transmembrane domain and kinase domain in the cytoplasm. Tyro3 receptor kinase belongs to the TAMRTK family. When Pros1 or Gas6 link to its immunoglobulinlike domain, Tyro3 receptor kinase is dimerized, tyrosine residues are phosphorylated and RTK is activated. High-level cytoplasmic Tyro3 receptor kinase may be activated even without its ligand $[42,43]$. It is shown that TAM receptors are especially expressed on macrophages, dendritic cells (DC), and endothelial cells [44]. It has been shown that thrombus formation and platelet aggregation are reduced in Tyro3 knockout groups, and also granule secretion is restricted [45].

Various studies have demonstrated that Tyro3 receptor kinase plays a role in cell growth, proliferation, invasion, and metastasis and is also an important regulator of EMT [46,47]. 


\section{Open Access Journal of Gynecology}

It is stated that Tyro3 receptor kinase has a role in cell proliferation, survival, migration, EMT, and platelet aggregation, which are important to continue of a healthy pregnancy. However, there is not enough knowledge related to expression levels and its localization of Tyro3 receptor kinase in human first trimester URPL.

Owing to a role for regulating EMT and platelet aggregation of Tyro3 receptor kinase, Tyro3 receptor kinase may be effective in the regulation of pregnancy and in acceptance to the uterus of an embryo which unfamiliar to the maternal genome. Thus, we have established the hypothesis that expression levels of Tyro3 receptor kinase show a difference in the decidua of Unexplained Recurrent Pregnancy Loss (UPRL) compared with a healthy pregnancy. For this reason, we aimed to determine the Tyro3 receptor kinase expression in the URPL decidua, which has a very important role in the initiation and maintenance of pregnancy, and to evaluate its possible relationship with URPL.

\section{Material and Methods}

\section{Antibodies and Reagents}

The following primary antibodies are used for immunohistochemistry and Immunoblotting Tyro3 (respectively, ab79778 [1:500], [1:1000]); for only immunoblotting beta-actin cell signaling \#4970 [1:1000], Secondary antibodies for Immunohistochemistry biotinylated goat anti-rabbit IgG BA-1000 (vector antibodies); for Immunoblotting HRP goat anti-rabbit IgG PI1000 (vector antibodies).

\section{Obtain of Samples and Ethics Statement}

We obtained tissue samples of our groups from volunteer women who participate in research that came to the OB/GYN department at the faculty of Medicine at Akdeniz University. The protocol was approved by the Research Ethics Committee of the faculty of medicine at Akdeniz University. Signed consents were obtained from each participant expressing that they voluntarily participated in the study. We were created by 3 groups as human first-trimester termination healthy pregnancy (TP) (n:6) and unexplained recurrent pregnancy losses (URPL) (n:6), and human endometrium (CE) (n:6). As well as women included in the RPL protocol had no previous live birth, they have two or more previous clinical miscarriages, where were included in the RPL protocol and unexplained their causes (for URPL). The TP group was obtained from the curettage material that was terminated upon the request of the patients who did not experience any spontaneous pregnancy loss. Endometrial biopsies taken from healthy women have been used for CE.

\section{Tissue Processing}

After we have obtained tissue samples, they were separated fetal and maternal parts under the invert stereomicroscope. As soon as the maternal part of the uterine tissue was fast washed by physiological saline solution $\% 9$, the tissues were separated into the 3 part. The first and second parts were used for RNA isolation and protein lysate as descripted below. The third part placed in a fresh $4 \%$ paraformaldehyde fixative for $24 \mathrm{~h}$ for fixation and after the tissue processing, embedded in Paraplast Plus (Leica) for immunohistochemistry.

\section{RNA Isolation and qPCR}

RNA isolation was performed using an RNAqueous micro-RNA isolation kit (Ambion). It is used an equal RNA amount for cDNA isolation (Ambion). After using RNase, the following qPCR (Rotorgene) conditions were used $95^{\circ} \mathrm{C} 5 \mathrm{~min}$, followed by 30 cycles of $92^{\circ} \mathrm{C} 30 \mathrm{sec}, 65^{\circ} \mathrm{C} 20 \mathrm{sec}$, and $72^{\circ} \mathrm{C} 1$ min by gene-specific primers at the table with SYBR Green PCR Master Mix (Applied Biosystems). Each amplification reaction was performed in triplicate and the amount of transcript in the sample was got an average of the mean and standard deviation of three threshold cycles. All values were normalized to an endogenous control (Gapdh).

Tyro 3 Forward Primer 5'-CCTGGCCGACAACCTGTAT-3' Tyro 3 Reverse Primer 5'TCCATTCGCAGACAAGTAAAGC-3' Gapdh Forward Primer 5' -GTCTTCACCACCATGGAGAA- 3' Gapdh Reverse Primer 5' -ATCCACAGTCTTCTGGGTGG-3'

As a result of the analysis of samples, quantitative realtime PCR with reference DNA and within the range of the standard we have created.

It was determined by reading on the device and using the software program. Tyro3 and Gapdh expression levels were quantitatively determined in the resulting threshold cycle and other cycles. Results were calculated using the method 2 [-Delta Delta C (T)] (2-CT). In this method, Ct values were determined by subtracting the $\mathrm{Ct}$ value of the tested gene and the $\mathrm{Ct}$ values given by the endogenous control for each sample separately.

\section{Protein Lysate Preparation and Immunoblotting}

Tissue samples were lysed in RIPA buffer (protein inhibitor cocktail [P8340; Sigma Aldrich]). The lysate was centrifuged at $15000 \mathrm{xg}$ for $10 \mathrm{~min}$ at $4^{\circ} \mathrm{C}$. Protein concentrations were quantified by Pierce modified Lowry protein assay kit (cat no: 23240). It was used in an equal amount of $50 \mu$ protein for immunoblotting. After it was used 


\section{Open Access Journal of Gynecology}

7,5\% acrylamide - polyacrylamide gel for electrophoresis, proteins were transferred to nitrocellulose membrane. Primary antibodies and secondary antibodies are used overnight at $4^{\circ} \mathrm{C}$ and 1 -hour room temperature, respectively. Immunoblot bands were quantified by Image analysis program.

\section{Immunohistochemistry}

Tyro 3 receptor kinase protein was immunostained on $5 \mu \mathrm{m}$ sections that were obtained from paraffinembedded human endometrial and decidual tissues; Immunohistochemistry protocol is created by overnight $4^{\circ} \mathrm{C}$ for primary antibody; $1 \mathrm{~h}$ room temperature for secondary antibodies. Antigen retrieval was conducted using boiling Tris EDTA. Diaminobenzidine tetrachloride (VECTOR) for ABC (HRP-6200-VECTOR) was used as the chromogens.

\section{Statistical Analysis}

Normality test was performed using the KolmogorovSmirnov test. One Way ANOVA/post hoc Tukey test was applied to determine whether there was a statistically significant difference between the groups, using the GraphPad (Prisms8) program, as deemed appropriate. Values with $\mathrm{p}<0.05$ were considered statistically significant. Their means are presented as \pm SEM.

\section{Results}

\section{Expression of Tyro3 Receptor Kinase in the Decidua of Human First-Trimester Unexplained Recurrent Pregnancy Losses}

To investigate Tyro3 receptor kinase expression, we firstly obtained human first-trimester healthy termination pregnancy and URPL samples. We separated fetal and maternal parts under the invert stereomicroscope. Maternal tissue was separated for immunohistochemistry, immunoblotting, and qPCR analyses. Firstly, we determined Tyro3 receptor kinase mRNA levels in decidual tissue using qPCR. Whereas mRNA expression significantly decreased $(\mathrm{P}=0,002)$ in TP decidua (TPD) compared with control endometrium (CE), increased in URPL decidua (URPLD) compared with TPD that similar to CE (Figure 1).

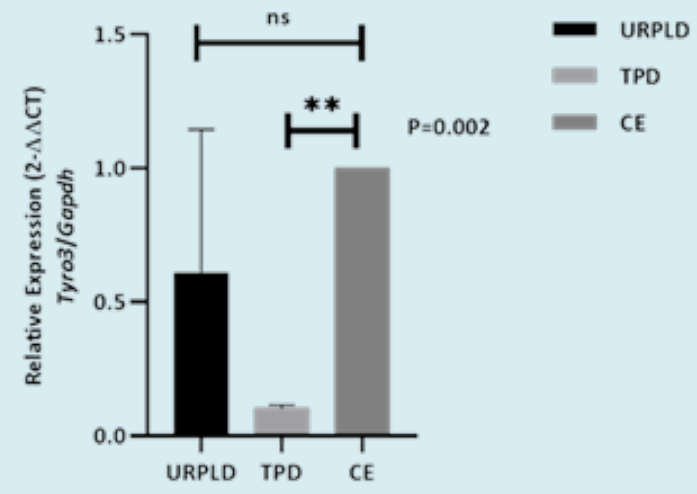

Figure 1: mRNA expression of the Tyro3 receptor kinase on URPLD, IPD and CE. Tyro3 receptor kinase mRNA expression significantly decreases on human first trimester

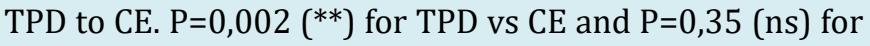
URPLD vs CE.

After the results of the mRNA expression, we wanted to determine whether does Tyro3 receptor kinase mRNA translates to protein, and Which cells do express Tyro3 receptor kinase in decidua and How do their localization between TPD and URPLD groups. Although the results of immunoblot analysis show parallel to qPCR, its results are non-significant (Figure 2).
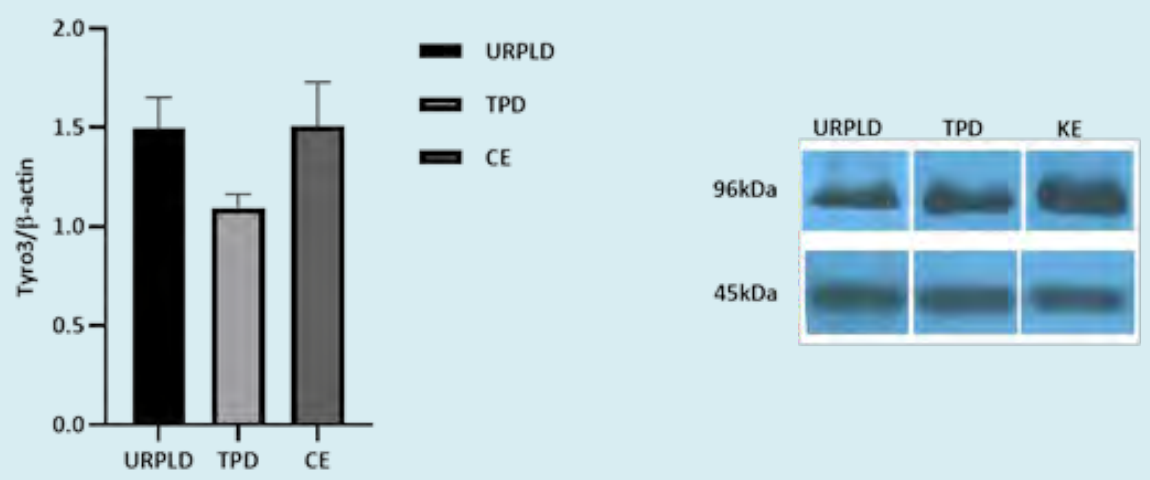

Figure 2: Results of Western blot analysis for Tyro3 receptor kinase among unexplained pregnancy loss decidua (URPLD), termination pregnancy decidua (TPD), and control endometrium (CE) groups. Tyro3 receptor kinase protein expression decreases on the TPD, not URPLD in the human first trimester to non-pregnancy. Result of all groups are non-significant (ns), $\mathrm{P}=0,21$ for URPLD vs TPD, $\mathrm{P}=0,19$ for TPD vs $\mathrm{CE}$ and $\mathrm{P}>0,99$ for URPLD vs $\mathrm{CE}$. 


\section{Open Access Journal of Gynecology}

In the results of the immunohistochemistry analysis, Tyro3 protein was viewed on both membrane for glandular epithelium and, in the nucleus for stromal cells of the CE. However, for TPD, there was weakly Tyro3 protein localization in the nucleus for decidual stromal cells that moderately expresses theirs both on the membrane and in the cytoplasmic. Moreover, Tyro3 protein expression was quite weak viewed in cytoplasmic and membranous for decidual stromal cells of UPRL group (Figure 3).

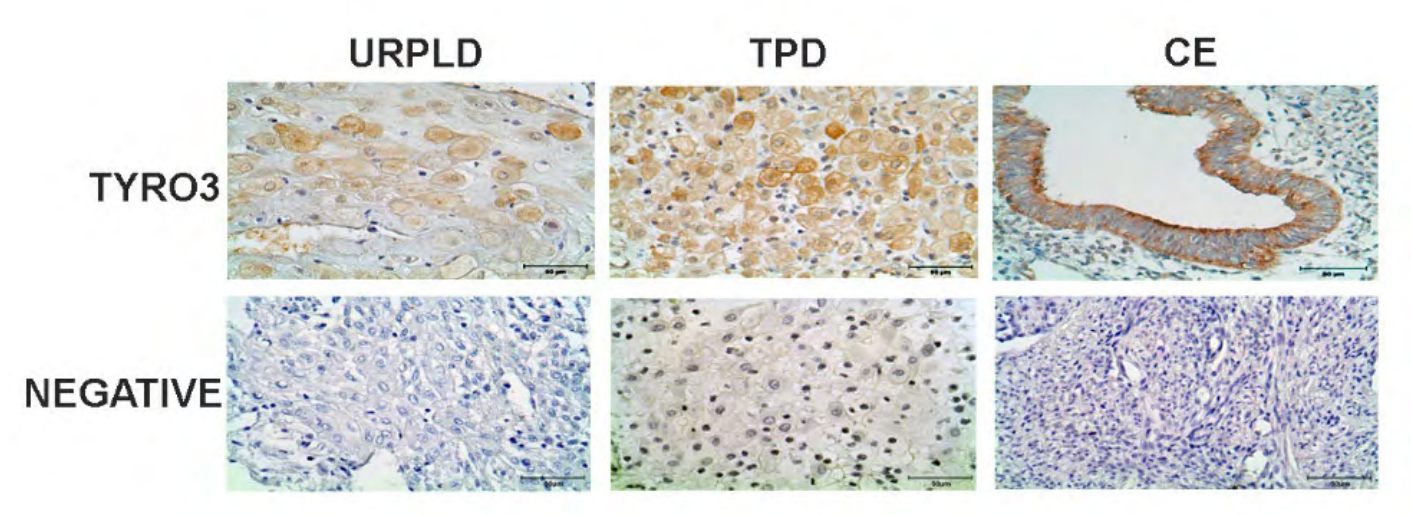

Figure 3: Immunohistochemistry staining of the Tyro3 receptor kinase on URPLD, TPD, and CE. Localization on DSCs of the Tyro3 receptor kinase protein shows with the black arrow.

\section{Discussion}

Adequate hemostatic balance and proper decidualization are essential to achieve a successful pregnancy. Obstetric complications such as recurrent pregnancy loss (RPL) may be due to placental perfusion disorder, possibly associated with an underlying prothrombotic condition. Also, impaired decidualization is strongly associated with recurrent pregnancy loss which indicates the importance of proper decidual cell maturation in maintaining a pregnancy $[10,48]$.

The human uterine endometrium has capable of rapid regeneration in monthly cycles, damage, and postpartum. However, cellular differentiation ability plays a very important role in human reproduction. While endometrial stromal cells undergo decidualization by showing mesenchymal-epithelial change for the implantation and continuity of the embryo, at the same time, luminal epithelial cells and decidual stromal cells gain the ability to move like mesenchymal cells by showing epithelial-mesenchymal transition through both embryo and maternal signals. Thus, decidual stromal cells also function in the development of the embryo by gaining the ability to accommodate invading trophoblasts [17]. Studies have shown that Tyro 3 receptor kinase facilitates cell growth and metastasis in cancer cells via the Wnt / betacatenin signaling pathway [46]. It is also in different studies that Tyro3 receptor kinase has a role in cell proliferation and invasion [47]. Studies are suggesting that overexpression of the Tyro3 receptor kinase accelerates EMT transformation and is an important regulator of EMT [46].
As a result of our work, while the total Tyro3 receptor kinase mRNA and protein levels of the decidua decreased significantly as a result of our immunoblot and qPCR analyzes, we found that it increased in URPL patients and almost reached the same level as the control endometrium. More interestingly, when we examined the localization of Tyro3 proteins as a result of our immunohistochemical analysis, in contrast to this decrease in total mRNA and protein levels, an increase in Tyro3 receptor kinase expression in the TP group and a decrease in the URPL group were observed in the decidual stromal cells. The results we found were that both decidual stromal cells and Tyro3 supported pregnancy parallel to their regulatory roles in EMT / MET transition and thrombotic activity. Considering the articles indicating that the presence of Tyro3 receptor kinase facilitates EMT; The more severe expression of the Tyro3 receptor kinase in decidual stromal cells during the first three months following implantation, as well as the higher both membranous and cytoplasmic expression, and the role of Tyro3 receptor kinase in gaining mesenchymal properties and supporting the embryo gives an idea. This idea should be supported by further functional studies.

During normal pregnancy, the hemostatic balance changes towards increased coagulation, thus reducing the bleeding complications associated with childbirth. Most blood clotting factors, and fibrinogen increase during pregnancy. The only blood coagulation factor to decrease is Factor (F) XI. Blood coagulation inhibitors are not changed, but the free protein $\mathrm{S}$ level is significantly reduced. During 


\section{Open Access Journal of Gynecology}

normal pregnancy, there is an activation of blood coagulation and an increase in fibrinolysis without signs of organ dysfunction [49].

Platelets are known for their contribution to hemostasis, wound healing, thrombosis, and inflammation. One study showed that endometriotic (endometriotic) stromal cells secrete thrombin and induce platelet activation. Normally, platelets in circulating blood are inactive. When a vessel wall is damaged, platelets are activated, aggregate, morphologically altered, degranulated, release many biologically active molecules and form a platelet plug [50].

Tyro3 receptor kinase has a critical role in immunity, hemostasis, and phagocytosis. a Gas6 null mouse study shows Tyro3 receptor kinase plays a role in platelet clusters [51]. In a Tyro3 receptor kinase knockout mouse study, it was shown that the granule secretion of platelets was restricted. It has been shown that thrombus formation and platelet aggregation are reduced in this strain [45].

In another study, Axl and Tyro3 receptor kinase have been shown to play a role in platelet activation and thrombus formation. In the study, platelet aggregation was inhibited by anti-Axl or anti-Tyro3 neutralizing antibodies. It has been suggested that inhibition is mechanically regulated through the extracellular domains of TAMs [52].

Since the role of Tyro3 receptor kinase in hemostasis, it suggests that this decrease observed in healthy pregnancy may have a role facilitate placental flow and thus can be regulated hemostasis in pregnancy through Tyro3 receptor kinase.

If these predictions support by further functional analyses, one of the causes of URPL can be lighted. Also, it may be a step various studies in the diagnosis or treatment of URPL.

\section{Authors Contributions}

Esma Kirimlioglu (Konuk), collected samples, and processed all of the tissue blocks, perform immunohistochemistry, immunoblotting, qPCR, and drafted the manuscript. Farida Qulieva (Xxx) also worked with Esma Kirimlioglu on immunoblotting. Mehmet Simsek received signed consent forms by providing the patients with the necessary information and providing them with the necessary information. Necdet Demir provided BAP (TDK2015-977) funding of the Akdeniz University and further assistance with data interpretation and writing of the manuscript.

\section{Source(s) of Funding}

This work was supported by BAP (TDK-2015-977) of the Akdeniz University.

\section{Conflict(s) of Interest/Disclosure(s)}

The authors declare no conflict of interest.

\section{References}

1. Christiansen OB (2013) Reproductive immunology. Mol Immunol 55(1): 8-15.

2. Cockburn K, Rossant J (2010) Making the blastocyst: lessons from the mouse. J Clin Invest 120(4): 995-1003.

3. Wang H,Dey SK(2006) Roadmap to embryo implantation: clues from mouse models. Nat Rev Genet 7(3): 185-199.

4. Modi DN, Godbole G, Suman P, Gupta SK (2012) Endometrial biology during trophoblast invasion. Front Biosci (Schol Ed) 4: 1151-1171.

5. Armant DR (2005) Blastocysts don't go it alone. Extrinsic signals fine-tune the intrinsic developmental program of trophoblast cells. Dev Biol 280(2): 260-280.

6. Turco MY, Gardner L, Richard G Kay, Russell S Hamilton, Malwina Prater, et al. (2018) Trophoblast organoids as a model for maternal-fetal interactions during human placentation. Nature 564(7735): 263-267.

7. Suman P, Malhotra SS, Gupta SK (2013) LIF-STAT signaling and trophoblast biology. JAKSTAT 2(4): e25155.

8. Shuang Zhang, Haiyan Lin, Shuangbo Kong, Shumin Wang, Hongmei Wang, et al. (2013) Physiological and molecular determinants of embryo implantation. Mol Aspects Med 34(5): 939-980.

9. PrabhuDas M, Bonney E, Caron K, Dey S, Erlebacher A, et al. (2015) Immune mechanisms at the maternal-fetal interface: perspectives and challenges. Nat Immunol 16(4): 328-334.

10. Salker M, Teklenburg G, Molokhia M, Lavery S, Trew G, et al. (2010) Natural selection of human embryos: impaired decidualization of endometrium disables embryomaternal interactions and causes recurrent pregnancy loss. PLoS One 5(4): e10287.

11. Nallasamy S, Li Q, Bagchi MK, Bagchi IC (2012) Msx homeobox genes critically regulate embryo implantation by controlling paracrine signaling between uterine stroma and epithelium. PLoS Genet 8(2): e1002500. 


\section{Open Access Journal of Gynecology}

12. Castro-Rendon WA, Castro-Alvarez JF, Guzmán-Martinez C, Bueno-Sanchez JC (2006) Blastocyst-endometrium interaction: intertwining a cytokine network. Braz J Med Biol Res 39(11): 1373-1385.

13. Hess AP, Hamilton AE, Talbi S, Dosiou C, Nyegaard M, et al. (2007) Decidual stromal cell response to paracrine signals from the trophoblast: amplification of immune and angiogenic modulators. Biol Reprod 76(1): 102-117.

14. Franco HL, Dai D, Lee KY, Rubel CA, Roop D, et al. (2011) WNT4 is a key regulator of normal postnatal uterine development and progesterone signaling during embryo implantation and decidualization in the mouse. FASEB J 25(4): 1176-1187.

15. Luan L, Ding T, Stinnett A, Reese J, Paria BC (2011) Adherens junction proteins in the hamster uterus: their contributions to the success of implantation. Biol Reprod 85(5): 996-1004.

16. Das SK (2009) Cell cycle regulatory control for uterine stromal cell decidualization in implantation. Reproduction 137(6): 889-899.

17. Owusu-Akyaw A, Krishnamoorthy K, Goldsmith LT, Morelli SS (2019) The role of mesenchymal-epithelial transition in endometrial function. Hum Reprod Update 25(1): 114-133.

18. Delorme MA, Burrows RF, Ofosu FA, Andrew M (1992) Thrombin regulation in mother and fetus during pregnancy. Semin Thromb Hemost 18(1): 81-90.

19. Lockwood CJ, Krikun G, Hickey M, Huang SJ, Schatz F (2009) Decidualized human endometrial stromal cells mediate hemostasis, angiogenesis, and abnormal uterine bleeding. Reprod Sci 16(2): 162-170.

20. Stirrat GM (1990) Recurrent miscarriage. II: Clinical associations, causes, and management. Lancet 336(8717): 728-733.

21. Practice Committee of the American Society for Reproductive Medicine (2012) Evaluation and treatment of recurrent pregnancy loss: a committee opinion. Fertil Steril 98(5): 1103-1111.

22. Regan L, Braude PR, Trembath PL (1989) Influence of past reproductive performance on risk of spontaneous abortion. BMJ 299(6698): 541-545.

23. Jeve YB, Davies W (2014) Evidence-based management of recurrent miscarriages. J Hum Reprod Sci 7(3): 159169.

24. Sugiura-Ogasawara M, Ozaki Y, Katano K, Suzumori
N, Mizutani E (2011) Uterine anomaly and recurrent pregnancy loss. Semin Reprod Med 29(6): 514-521.

25. Yetman DL, Kutteh WH (1996) Antiphospholipid antibody panels and recurrent pregnancy loss: prevalence of anticardiolipin antibodies compared with other antiphospholipid antibodies. Fertil Steril 66(4): 540-546.

26. Balszan-Kowalska I (2002) Diagnosis of thrombophilia based on coagulation and genetic studies. Ann Acad Med Stetin 48: 179-193.

27. Dizon-Townson D, Miller C, Sibai B, Spong CY, Thom E, et al. (2005) The relationship of the factor $V$ Leiden mutation and pregnancy outcomes for mother and fetus. Obstet Gynecol 106(3): 517-524.

28. Silver RM, Zhao Y, Spong CY, Sibai B, Wendel G, et al. (2010) Prothrombin gene G20210A mutation and obstetric complications. Obstet Gynecol 115(1): 14-20.

29. Steegers-Theunissen RP, Boers GH, Blom HJ, Rrijbels FJ, Eskes TK (1992) Hyperhomocysteinaemia and recurrent spontaneous abortion or abruptio placentae. Lancet 339(8801): 1122-1123.

30. Nelen WL, Blom HJ, Steegers EA, den Heijer M, Eskes TK (2000) Hyperhomocysteinemia and recurrent early pregnancy loss: a meta-analysis. Fertil Steril 74(6): 1196-1199.

31. Leitich H, Kiss H (2007) Asymptomatic bacterial vaginosis and intermediate flora as risk factors for adverse pregnancy outcome. Best Pract Res Clin Obstet Gynaecol 21(3): 375-390.

32. Liddell HS, Sowden K, Farquhar CM (1997) Recurrent miscarriage: screening for polycystic ovaries and subsequent pregnancy outcome. Aust $\mathrm{N} \mathrm{Z} \mathrm{J} \mathrm{Obstet}$ Gynaecol 37(4): 402-406.

33. Rai R, Backos M, Rushworth F, Regan L (2000) Polycystic ovaries and recurrent miscarriage-a reappraisal. Hum Reprod 15(3): 612-615.

34. Chakraborty P, Goswami SK, Rajani S, Sharma S, Kabir SN, et al. (2013) Recurrent pregnancy loss in polycystic ovary syndrome: role of hyperhomocysteinemia and insulin resistance. PLoS One 8(5): e64446.

35. Saito S, Nakashima A, Shima T (2011) Future directions of studies for recurrent miscarriage associated with immune etiologies. J Reprod Immunol 90(1): 91-95.

36. Russell P, Anderson L, Lieberman D, Tremellen K, Yilmaz $\mathrm{H}$, et al. (2011) The distribution of immune cells and 


\section{Open Access Journal of Gynecology}

macrophages in the endometrium of women with recurrent reproductive failure I: Techniques. J Reprod Immunol 91(1-2): 90-102.

37. Reus AD, Besouw NMV, Molenaar NM, Steegers EAP, Visser W, et al. (2013) An immunological basis for chronic histiocytic intervillositis in recurrent fetal loss. Am J Reprod Immunol 70(3): 230-237.

38. Robinson DR, Wu YM, Lin SF (2000) The protein tyrosine kinase family of the human genome. Oncogene 19(49): 5548-5557.

39. Lai C, Lemke G (1991) An extended family of proteintyrosine kinase genes differentially expressed in the vertebrate nervous system. Neuron 6(5): 691-704.

40. Stitt TN, Conn G, Gore M, Lai C, Bruno J, et al. (1995) The anticoagulation factor protein $\mathrm{S}$ and its relative, Gas6, are ligands for the Tyro 3/Axl family of receptor tyrosine kinases. Cell 80(4): 661-670.

41. Nagata K, Ohashi K, Nakano T, Arita H, Zong C, et al. (1996) Identification of the product of growth arrestspecific gene 6 as a common ligand for Axl, Sky, and Mer receptor tyrosine kinases. J Biol Chem 271(47): 3002230027.

42. Sasaki T, Knyazev PG, Clout NJ, Cheburkin Y, Göhring W, et al. (2006) Structural basis for Gas6-Axl signalling. EMBO J 25(1): 80-87.

43. Hsu PL, Jou J, Tsai SJ (2019) TYR03: A potential therapeutic target in cancer. Exp Biol Med (Maywood) 244(2): 83-99.

44. Zagorska A, Través PG, Lew ED, Dransfield I, Lemke G, et al. (2014) Diversification of TAM receptor tyrosine kinase function. Nat Immunol 15(10): 920-928.

45. Angelillo-Scherrer A, Burnier L, Flores N, Savi P, DeMol M, et al. (2005) Role of Gas6 receptors in platelet signaling during thrombus stabilization and implications for antithrombotic therapy. J Clin Invest 115(2): 237-246.

46. Chen D, Liu Q, Cao G, Zhang W (2020) TYRO3 facilitates cell growth and metastasis via activation of the Wnt/ beta-catenin signaling pathway in human gastric cancer cells. Aging (Albany NY) 12(3): 2261-2274.

47. Dufour F, Silina L, Neyret-Kahn H, Moreno-Vega A, Krucker C, et al. (2019) TYRO3 as a molecular target for growth inhibition and apoptosis induction in bladder cancer. Br J Cancer 120(5): 555-564.

48. Lucas ES, Dyer NP, Murakami K, Lee YH, Chan YW, et al. (2016) Loss of Endometrial Plasticity in Recurrent Pregnancy Loss. Stem Cells 34(2): 346-356.

49. Hellgren M (2003) Hemostasis during normal pregnancy and puerperium. Semin Thromb Hemost 29(2): 125-30.

50. Guo SW, Du Y, Liu X (2016) Endometriosis-Derived Stromal Cells Secrete Thrombin and Thromboxane A2, Inducing Platelet Activation. Reprod Sci 23(8): 10441052.

51. Angelillo-Scherrer A, de Frutos P, Aparicio C, Melis E, Savi P, et al. (2001) Deficiency or inhibition of Gas6 causes platelet dysfunction and protects mice against thrombosis. Nat Med 7(2): 215-221.

52. Zhou J, Yang A, Wang Y, Chen F, Zhao Z, et al. (2018) Tyro3, Axl, and Mertk receptors differentially participate in platelet activation and thrombus formation. Cell Commun Signal 16(1): 98. 